\title{
GUAVIARE: REENCONTRANDO ESPACIOS E IDENTIDADES
}

Por Cristian Alexis Gil Ruiz ${ }^{1}{ }^{1}$ Estudiante de Octavo semestre Licenciatura en Biología. Universidad Pedagógica Nacional. 2010

La riqueza colombiana está en las selvas, claro, la faunística y florística que enluce a nuestro querido país, a continuación les mostraré rasgos de esa riqueza encontrada en el departamento del Guaviare, más exactamente en la vereda cerro azul, en un sitio llamado Cerro pinturas y que es un patrimonio cultural y arqueológico del departamento, espacios como hay en muchos escenarios de Colombia, que es un país hermoso, con varios sitios que no se han visitado, y que son dignos de ver, es triste que como estudiantes, como docentes en formación y más que todo, como colombianos, nos estemos perdiendo estas oportunidades.

Además de ello debe entenderse al docente como un sujeto no sólo educativo, también es un sujeto con vocación social, política y cultural y que sea como sea, es un ciudadano y nunca dejara de serlo, así que como docentes es nuestro deber apropiarnos de sitios como éste y educar para que sean admirados, protegidos y sobre todo respetados.

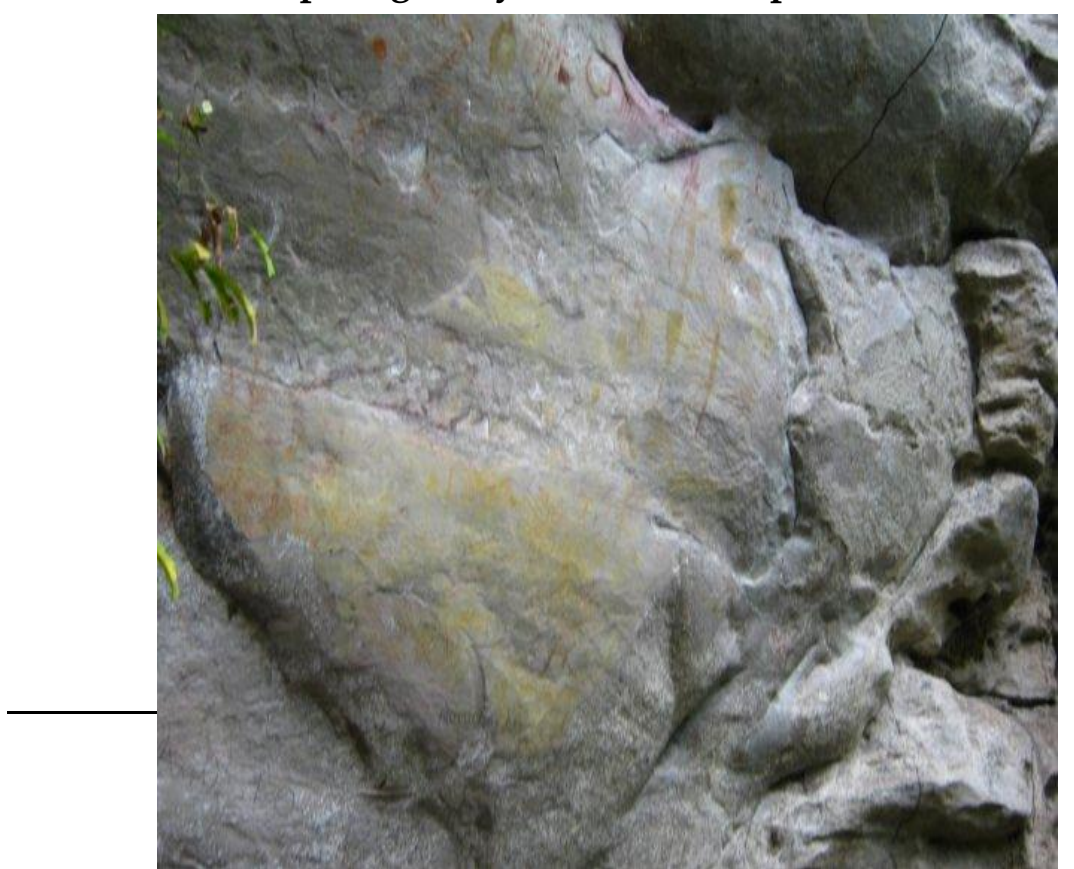

Las imponentes rocas del lugar conocido como cerro pinturas

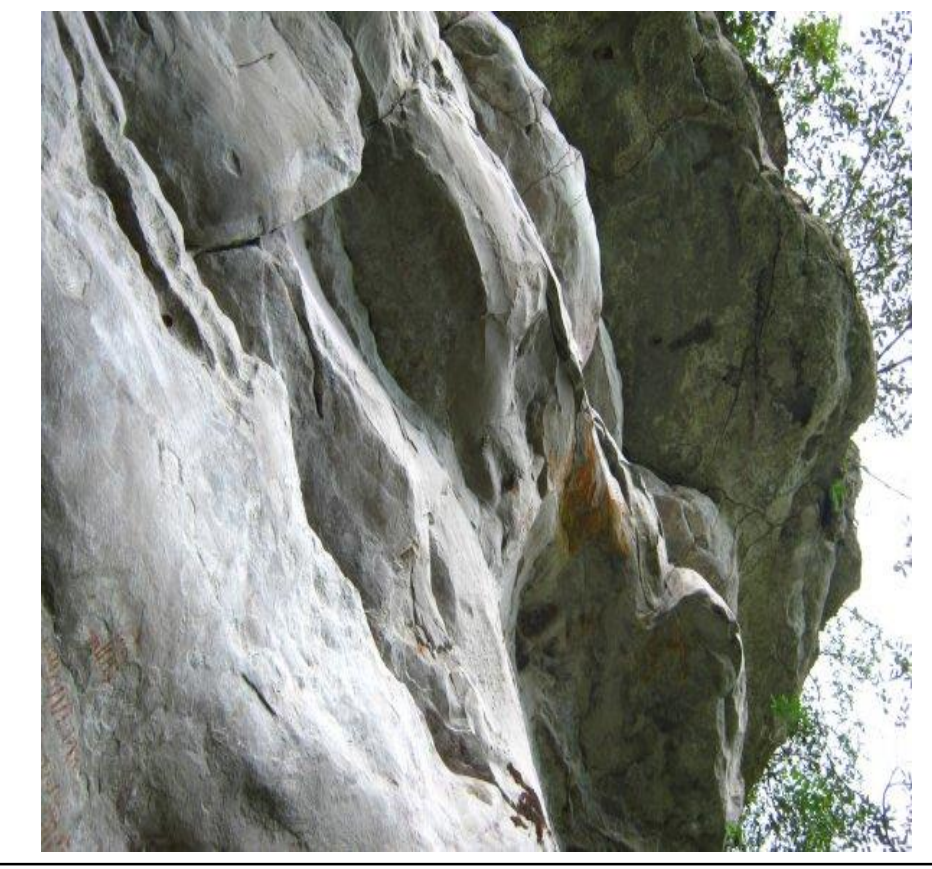

Esta formación rocosa es muy antigua, y puede confundirse con un tepuye. 


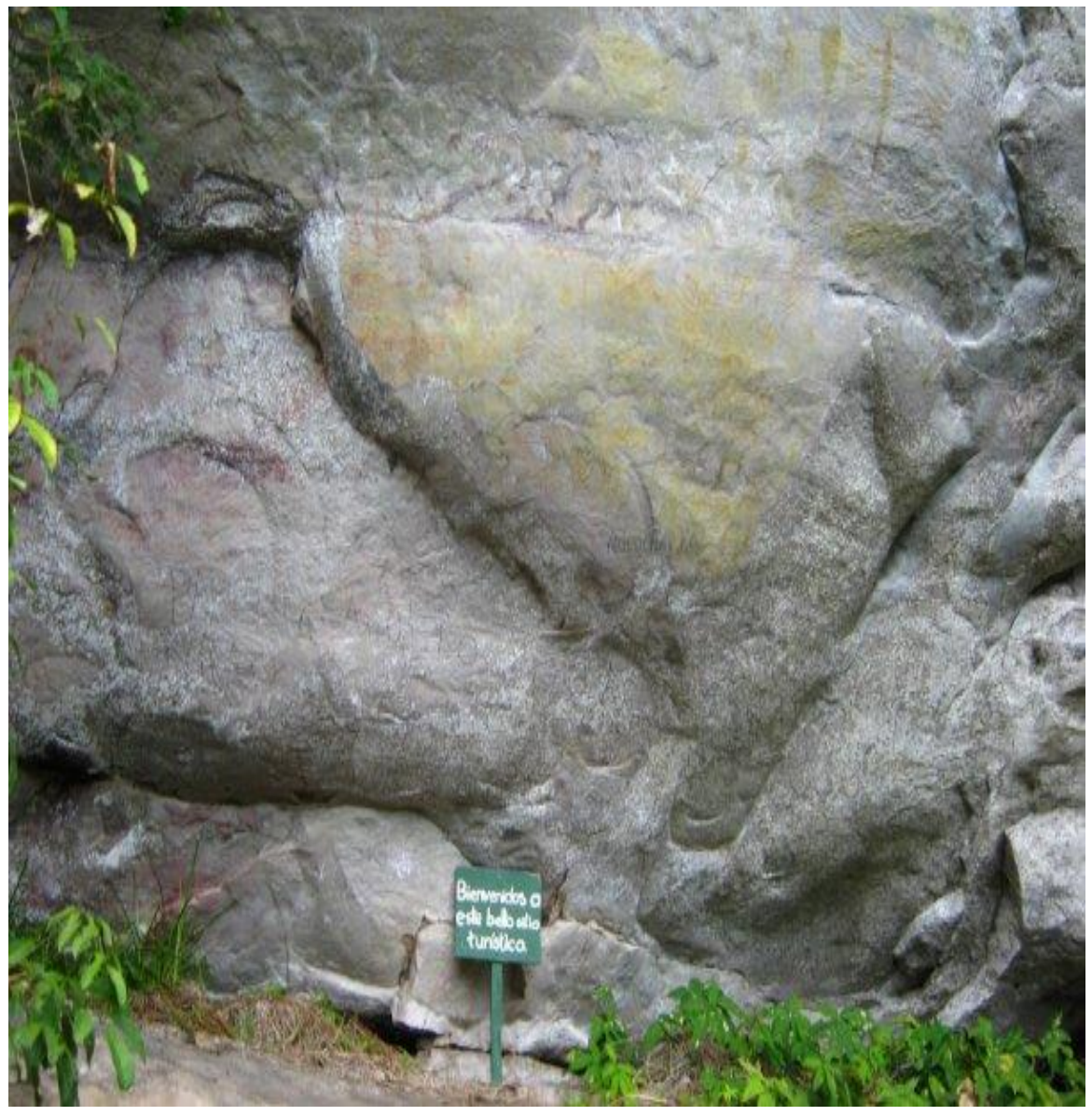

Estas pinturas han fueron hechas aproximadamente hace 150 años

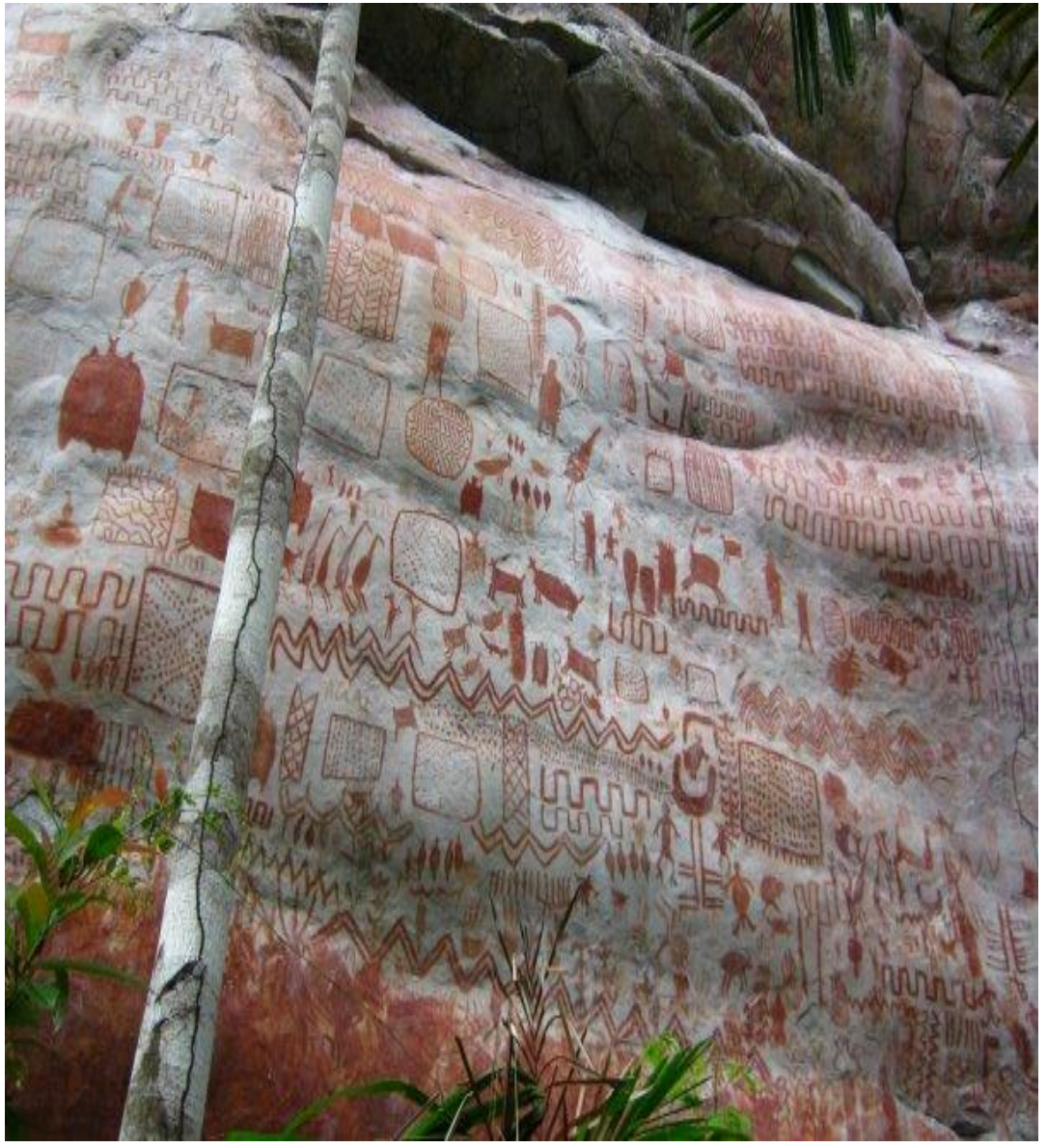

ofrecen un hermoso espectáculo que nos reencuentra con nuestra identidad. 

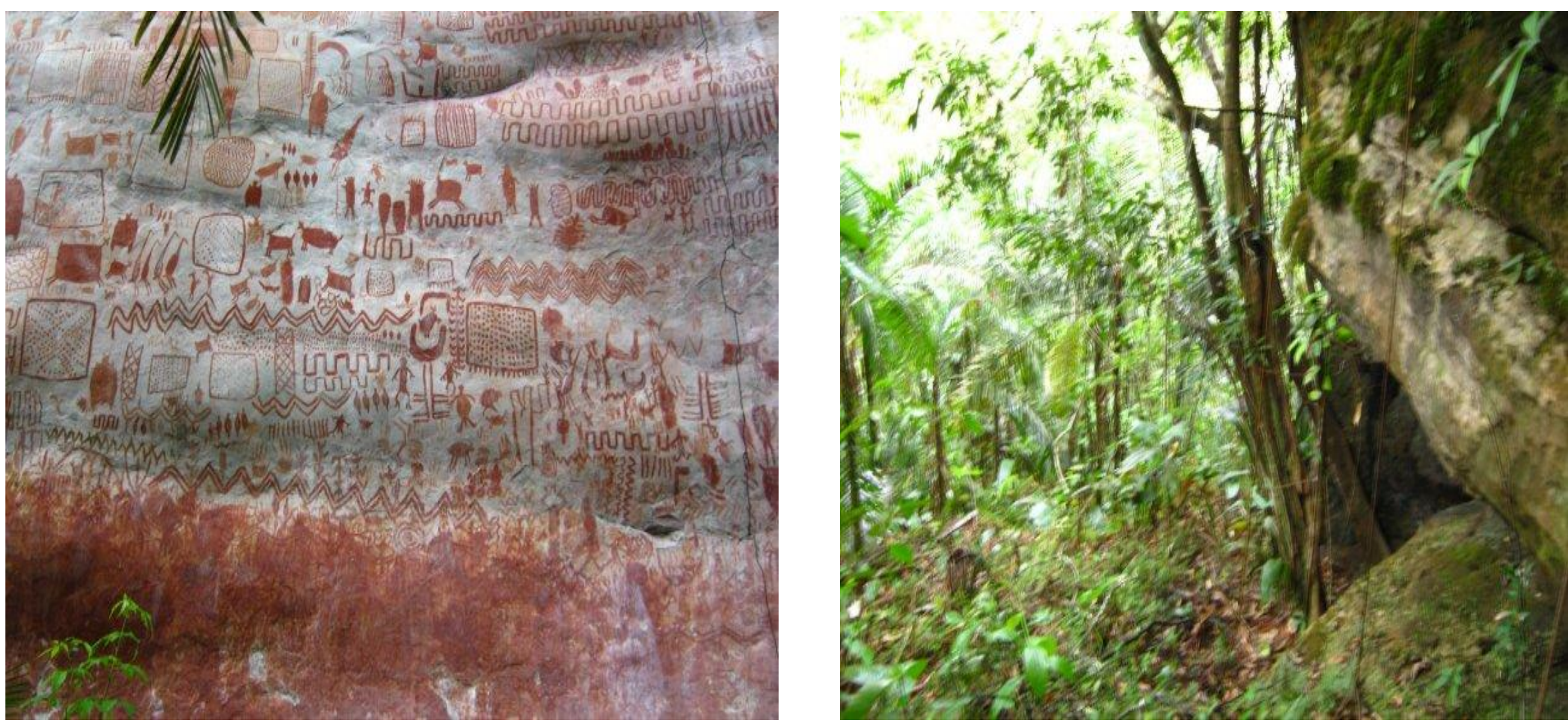

La calidad de las pinturas se mantiene intacta a pesar del paso del

Este lugar se camufla en la selva y se encierra en una fortaleza tiempo y del mal cuidado 


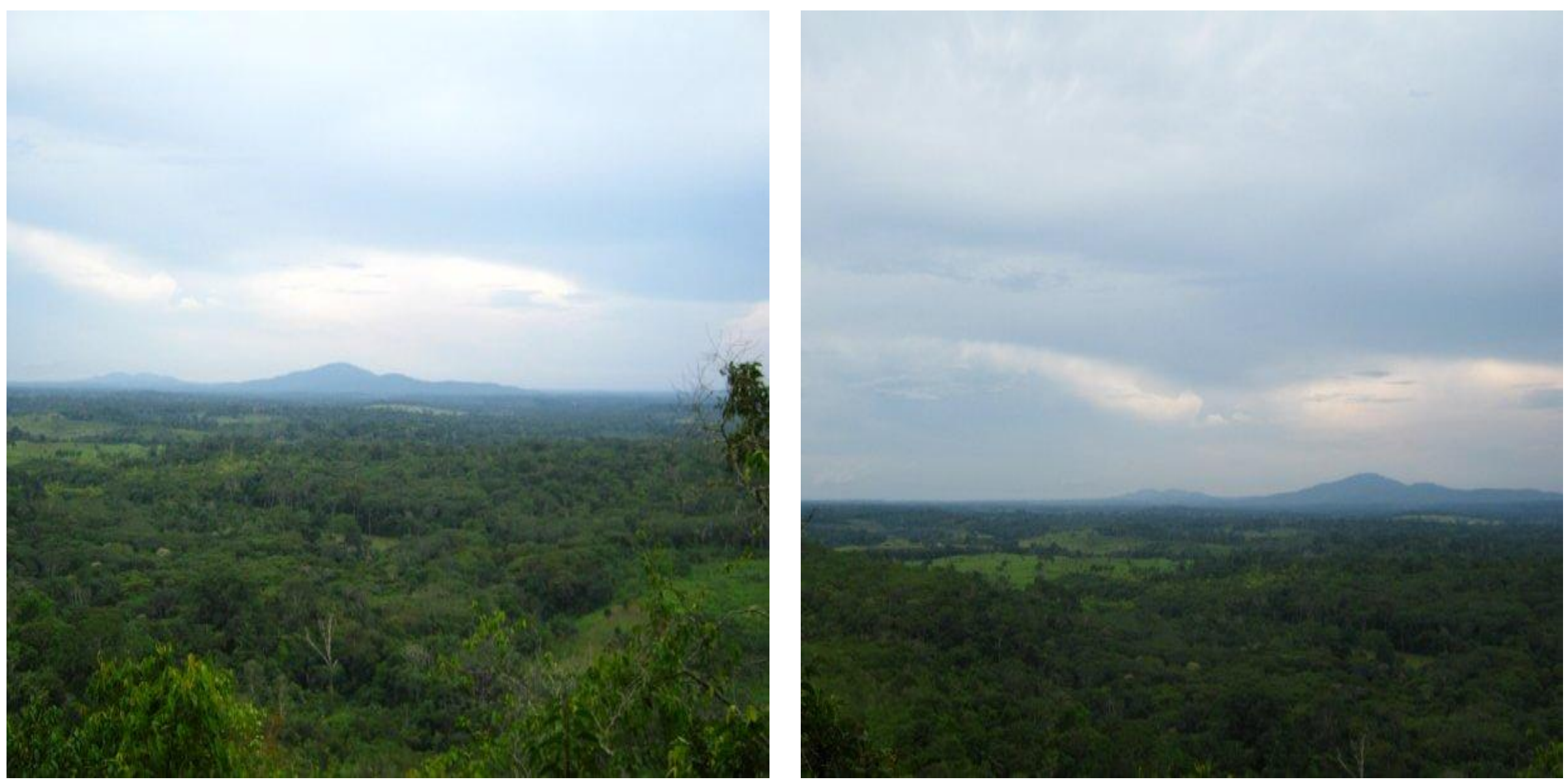
otras obras de arte. 

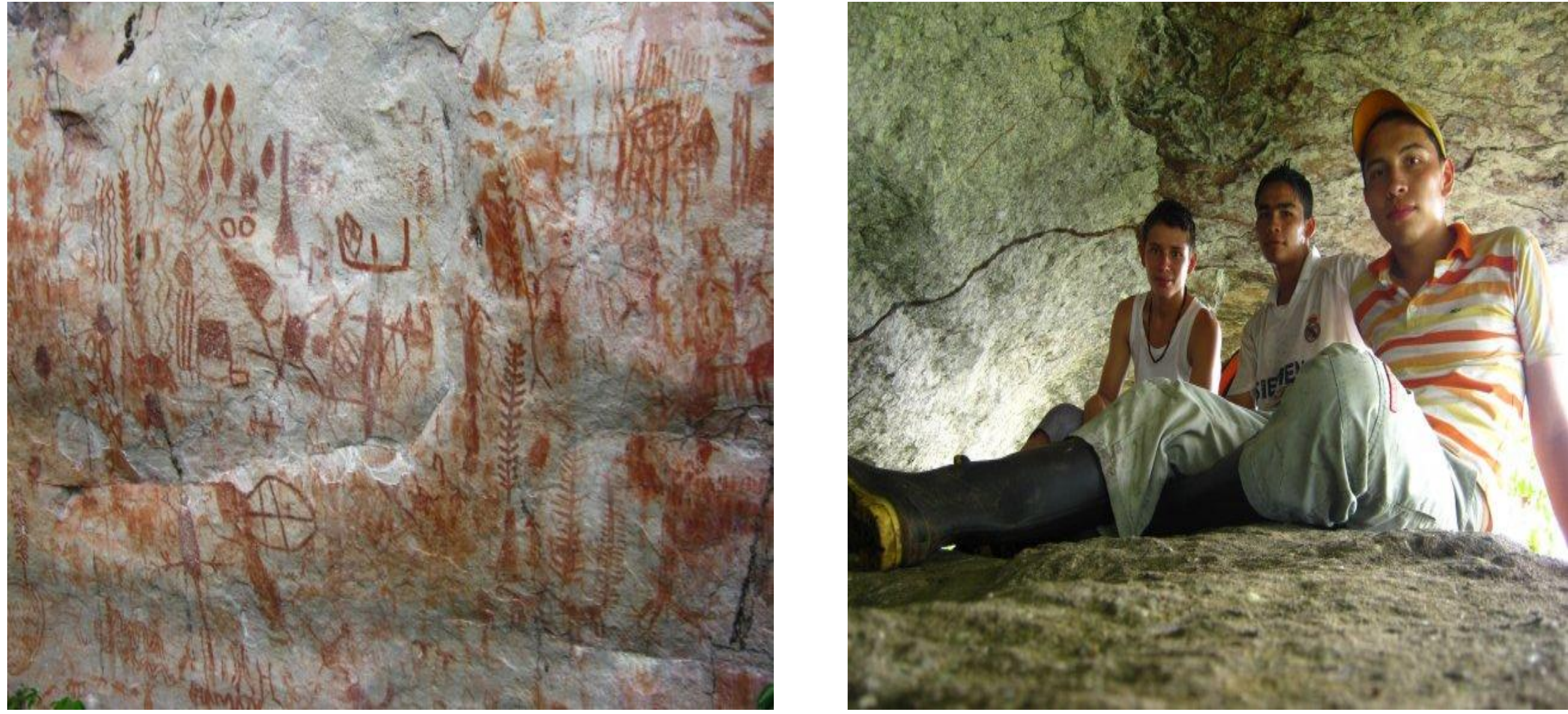

Este recorrido no hubiese sido posible sin el acompañamiento de dos queridos estudiantes que hicieron el papel de guisas también. 


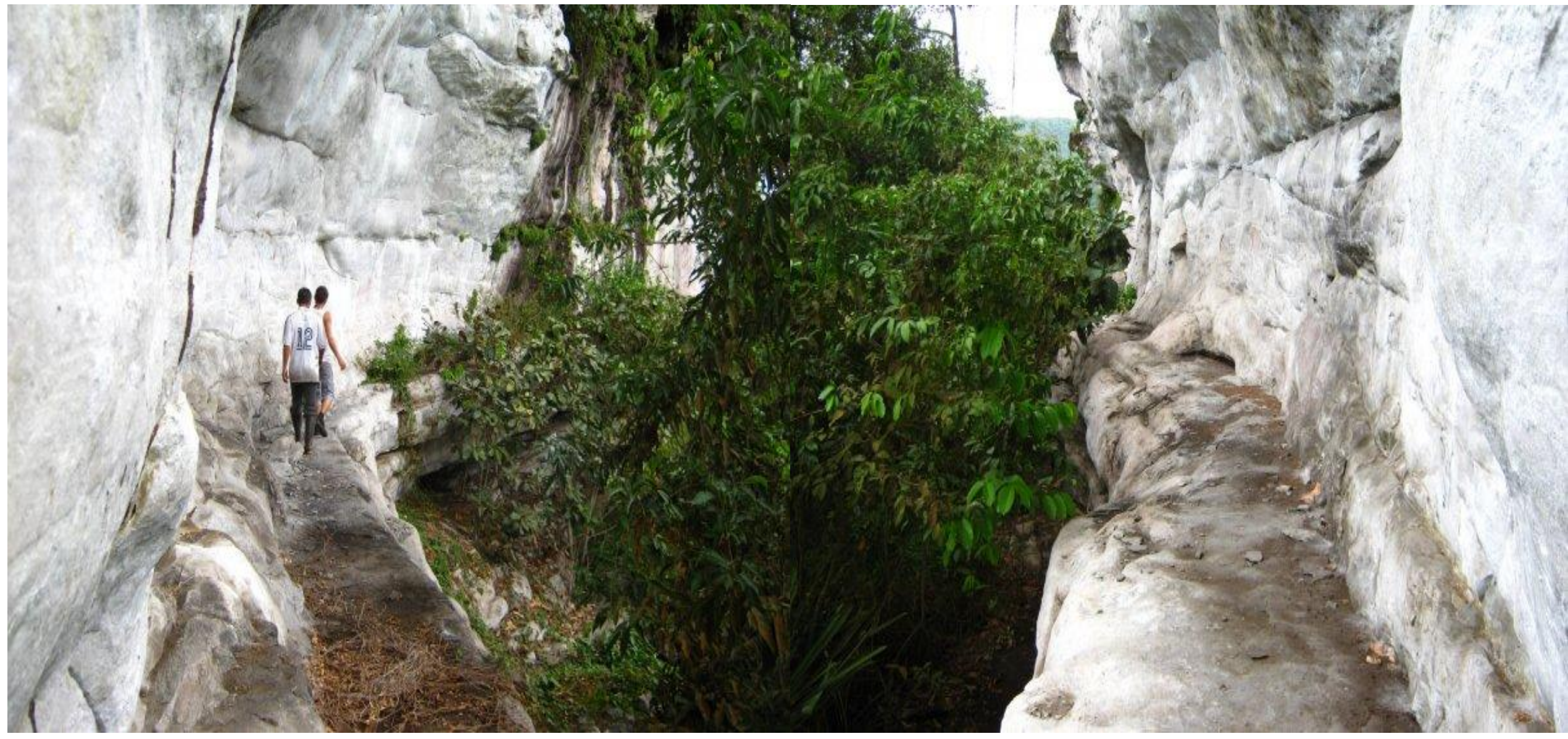

Para llegar a cada una de las pinturas, hay que atravesar algunos obstaculos de montaña, por ejemplo, este pasilllo, creado por las rocas. 

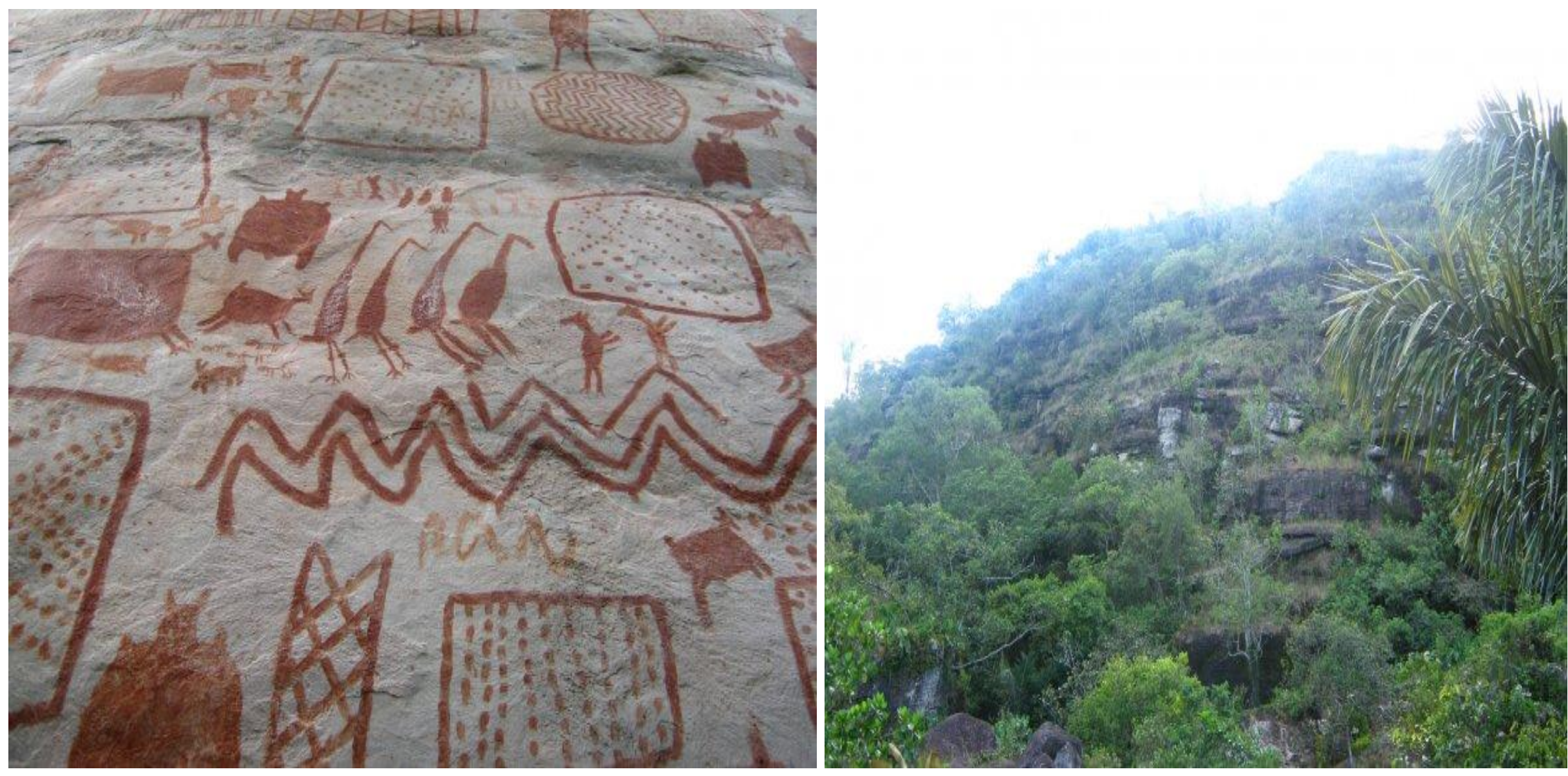

Espacios como este nos muestran que en colombio hay muchos lugares que debemos conocer.

Formación rocosa común dentro de los paisajes llaneros. 


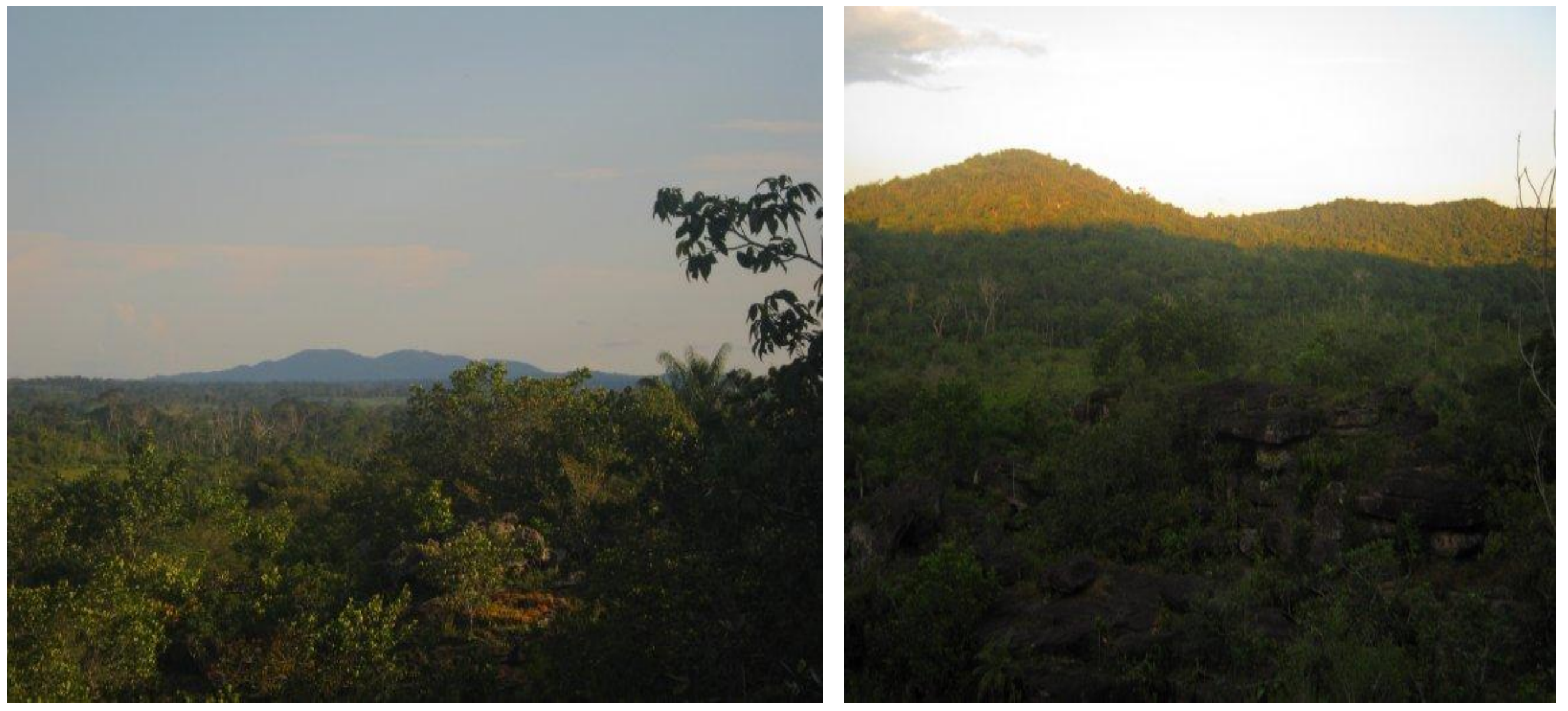

El atardecer cae maravillando la vista, enriqueciendo el paisaje y despidiendo esta aventura... 